\title{
EMI Reduction of a Soft-switched High Step- down Converter Using Passive Compensation Method
}

\author{
Mohammad Rouhollah Yazdani \\ Dept. of Electrical and Computer Engineering \\ Isfahan (Khorasgan) Branch, Islamic Azad \\ University \\ Isfahan, Iran \\ m.yazdani@khuisf.ac.ir
}

\author{
Ali Ariyan \\ Dept. of Electrical and Computer Engineering \\ Isfahan (Khorasgan) Branch, Islamic Azad \\ University \\ Isfahan, Iran \\ aliarian68@gmail.com
}

\begin{abstract}
In this paper, an EMI reduction method is applied to a new high step-down converter which has a coupled inductor, a synchronous rectifier and method with an auxiliary soft-switching cell. The freewheeling diode is replaced with a synchronous rectifier (SR) and zero-voltage-transition (ZVT) condition is provided for the main and SR switches. The auxiliary switch acts under zero-current switching. To reduce conducted electromagnetic emissions, a passive method is utilized by adding another winding on the core of converter coupled inductor to compensate the common-mode noise current generated by the parasitic capacitor of the main switch. The operating modes and theoretical waveforms are presented and simulation results of a $100 \mathrm{~W}-100 \mathrm{kHz}$ converter are shown to verify the theoretical analysis. The conducted EMI predictions confirm the benefit of the passive compensation method.
\end{abstract}

Keywords- Electromagnetic interference (EMI); High step-down converter; Heat-sink capacitor; Passive compensation; Soft switching

$V_{\text {in }}$ : Input voltage

\section{NOMENCLATURE}

$S$ : Main switch

$D_{s}$ : Body diode of the main switch

$C_{s}$ : Snubber capacitor

$S_{r}:$ Synchronous switch

$D_{r}$ : Body diode of synchronous switch

$S_{a}$ : Auxiliary switch

$L_{a}$ : Auxiliary inductor

$C$ : Output capacitor

$R$ : Load resistance

$D$ : Duty cycle

$I_{O}$ : Output current

ZCS: Zero-current switching

ZVS: Zero-voltage switching

LISN: Line Impedance Stabilization Network

\section{INTRODUCTION}

Nowadays, there are many applications that require step-down or step-up voltage conversion ratio in renewable energy conversion [1-2]. Buck converters are used in applications that need low voltage and high current [3-4] like batteries [3-5]. Due to the limitation of the regular buck converter with small duty ratio, the conventional buck converter is not suitable for high step-down voltage conversion. To reduce the conduction losses, a synchronous rectifier can be used instead of the freewheeling diode in the buck topology [6].

In [7], a quadratic buck converter is introduced to extend the duty cycle for high step-down conversion but the voltage stress of switch is high. One way for extending the duty cycle to achieve high step-down conversion is the tapped-inductor topology [8].

Since the operation under hard switching condition causes some bad effects on the efficiency of the converter and electromagnetic compatibility (EMC), which is due to high di/dt and dv/dt, soft switching techniques are employed to decrease switching losses and electromagnetic interference (EMI).Both zerovoltage-switching (ZVS) and zero-current-switching (ZCS) are soft switching methods that can be used in the buck topology [9]. In [10-11], soft switching stepdown converters with coupled inductor are presented. In [10], a buck converter with a coupled inductor is proposed in which the main switch turns on under ZCS condition. Nevertheless, the voltage conversion ratio is equal to the traditional buck converter. Also because of the additional diode's conduction losses, the efficiency is reduced. In [11], an auxiliary switch, a diode and a coupled inductor are added to the conventional buck converter to provide zero-voltage switching in the turn-on instant, but the problem was that the voltage conversion ratio is equal to conventional buck converter and output current ripple is larger than a traditional buck converter.

The EMI reduction by some soft switching topologies may not satisfy EMC standard leading to implementing other EMI reduction methods. This paper focuses on compensating the common-mode (CM) noise current generated by the main switch heatsink capacitor. For this purpose, an auxiliary winding and a capacitor are added to the converter circuit to reduce conducted EMI.

In this paper, a high step-down buck converter using an auxiliary soft switching cell and a synchronous rectifier [12] without clamp circuit is briefly studied. In addition to the high step-down conversion of the converter, $\mathrm{ZV}$ condition is provided for the main and synchronous rectifier switches and 
the auxiliary switch operates under zero-current switching condition. After the theoretical analysis and the study operation modes have done in section II, design procedure and simulation results are presented in section III including important current and voltage waveforms and the EMI prediction of the converter before and after applying a passive compensation method. Finally, section V summarizes the conclusions of this paper.

\section{CIRCUIT DESCRIPTION AND OPERATION}

The high step down converter is shown in Fig. 1. The converter is composed of the main switch $S$, a synchronous rectifier $S_{r}$, and a tapped-inductor $L_{1}, L_{2}$. The auxiliary circuit is composed of unidirectional switch $S_{a}$ and $L_{a}$. In order to simplify the converter analysis, it is assumed that semiconductor devices are ideal and $L_{2}$ current is constant $\left(I_{o}\right)$ in a switching cycle.

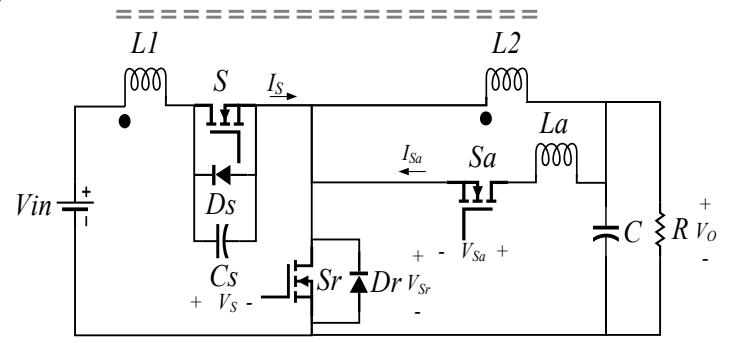

Figure 1. soft-switching high step down converter

Ideal waveforms of the soft-switching high step down converter are shown in Fig. 2. It is assumed that before the first mode, $S_{r}$ is conducting and other semiconductor devices are off. The equivalent circuit for each operating mode is also presented in Fig. 3.

Mode $1\left[t_{0}-t_{1}\right]$, Fig. 3(a): $S_{a}$ starts to conduct and it turns on under zero current switching due to the existence of $L_{a}$ inductor. During this mode, $L_{a}$ current increases linearly to $I_{o}$ because $V_{o}$ is placed across $L_{a}$. Also, $S_{r}$ current decreases from $I_{o}$ to zero. The current through $L_{a}$ during this mode is as below:

$$
I_{L a}=\frac{V_{o}\left(t-t_{0}\right)}{L_{a}}
$$

Mode $2\left[t_{1}-t_{2}\right]$, Fig. 3(b): In this mode, $S_{r}$ is on; hence, $L_{a}$ current increases linearly from $I_{o}$ to its maximum value $I_{l}$. It is noted that this additional energy in $L_{a}$ is used to discharge $C_{s}$ in the next mode. Also, at the end of this mode, the current of synchronous rectifier reaches $I_{l}-I_{o}$ and $I_{L a}$ is achieved as:

$$
I_{L a}=I_{o}+\frac{V_{o}\left(t-t_{1}\right)}{L_{a}}
$$

Mode $3\left[t_{2}-t_{3}\right]$, Fig. 3(c): At $t_{2}, S_{r}$ turns off under ZVS condition due to the snubber capacitor $C_{s}$ and a resonance happens between $L_{a}$ and $C_{s}$. Thereby, at the end of this mode, $C_{s}$ is completely discharged and also $L_{a}$ current reaches $I_{2}$ which is slightly higher than $I_{o}$. The resonant frequency in this mode is defined by:

$$
\omega_{0}=\frac{1}{\sqrt{L_{a} C_{s}}}
$$

Mode $4\left[t_{3}-t_{4}\right]$, Fig. $3(d): L_{a}$ current decreases linearly to $I_{o}$ and $D_{s}$ starts to conduct; consequently, main switch $S$ can be turned on under ZVS condition. In this mode, $L_{a}$ current is written as below.

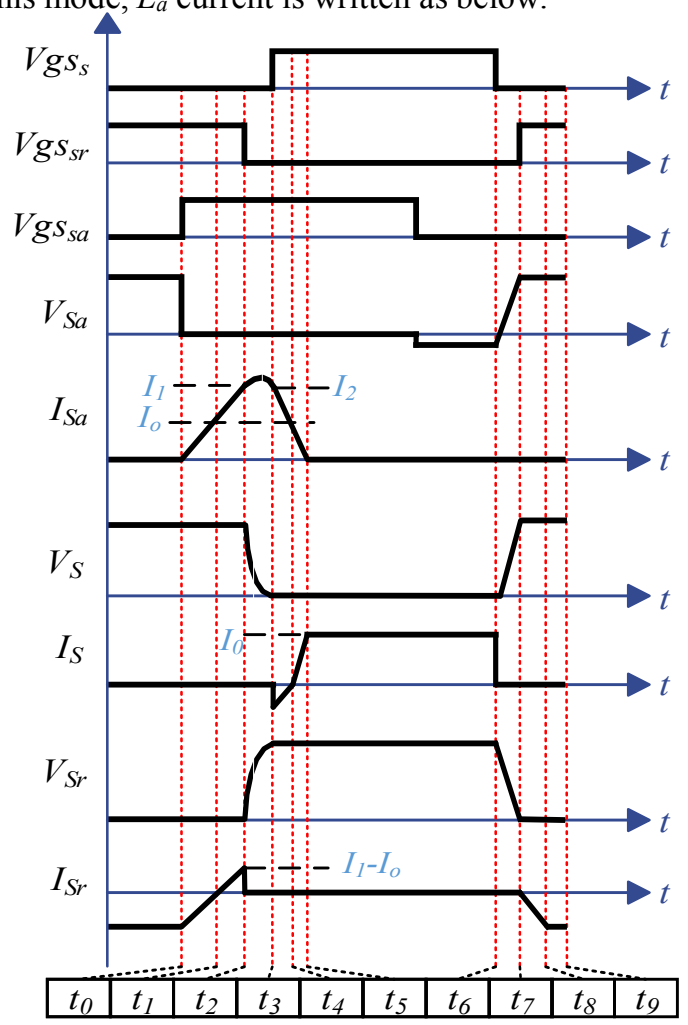

Figure 2. Typical waveforms of the high step down converter

$$
I_{L a}=I_{2}-\frac{n \cdot\left(V_{i n}-V_{o}\right)}{(n+1) \cdot L_{a}} .\left(t-t_{3}\right)
$$

Mode $5\left[t_{4}-t_{5}\right]$, Fig. 3(e): In this mode, $S$ is on and $L_{a}$ current continues its reduction linearly. At the end of this mode, $I_{L a}$ reaches zero and the current through the main switch $S$ reaches $I_{0}$.

$$
I_{L a}=I_{o}-\frac{n \cdot\left(V_{i n}-V_{o}\right)}{(n+1) \cdot L_{a}} \cdot\left(t-t_{4}\right)
$$

where $n: n_{2} / n_{1}$ is the turn ratio.

Mode $6\left[t_{5}-t_{6}\right]$, Fig. $3(f)$ : In this mode, the main switch remains on and it transfers the input energy to the output port.

Mode $7\left[t_{6}-t_{7}\right]$, Fig. 3(g): This mode starts by turning off the main switch, $S$ and thus $C_{s}$ starts to charge. Due to the snubber capacitor $C_{s}$, main switch turn-off is under ZVS.

Mode $8\left[t_{7}-t_{8}\right]$, Fig. $3(h)$ : At the beginning of this mode $C_{s}$ has a constant voltage and $D_{r}$ starts to conduct. Hence, $S_{r}$ can be turned on under ZVS condition at any time during the $8^{\text {th }}$ mode. In this mode, the current through $S_{r}$ increases linearly and by the end of this mode, $I_{S r}$ reaches $I_{o}$.

Mode 9 [t $\left.t_{8}-t_{9}\right]$, Fig. 3(i): In this mode, the output current flows through $S_{r}$ and $L_{2}$. This mode continues until the gate pulse of $S_{a}$ is applied and the next cycle of switching starts. 


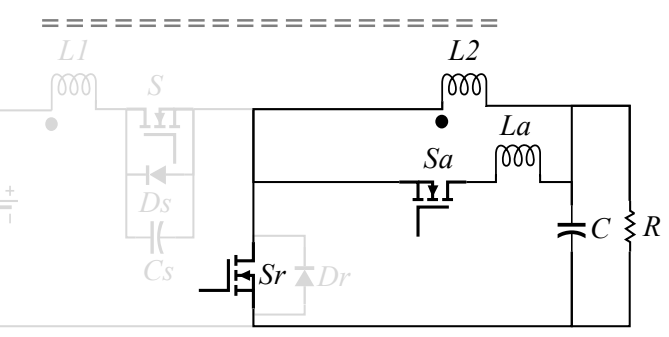

(a)

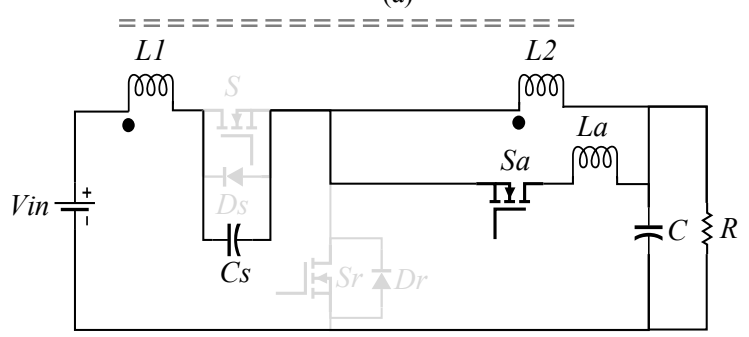

(c)

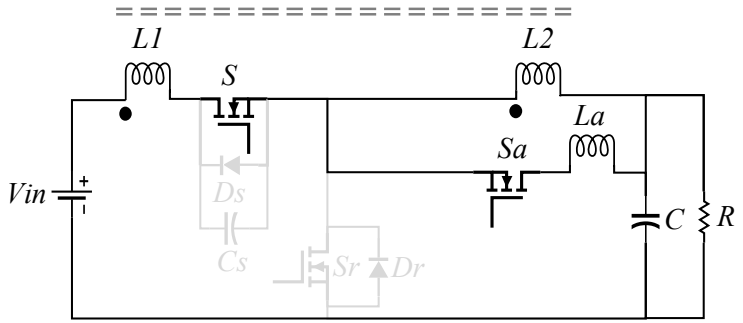

(e)

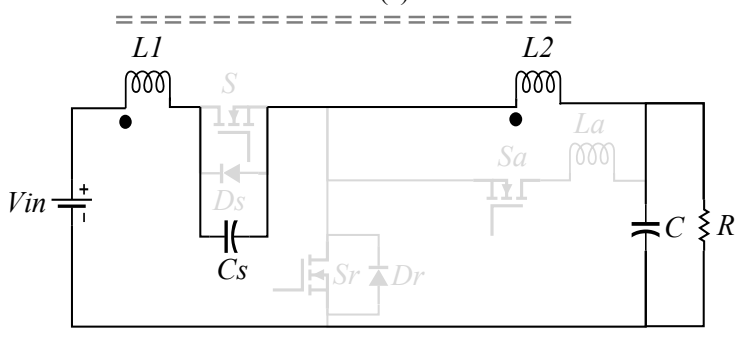

(g)

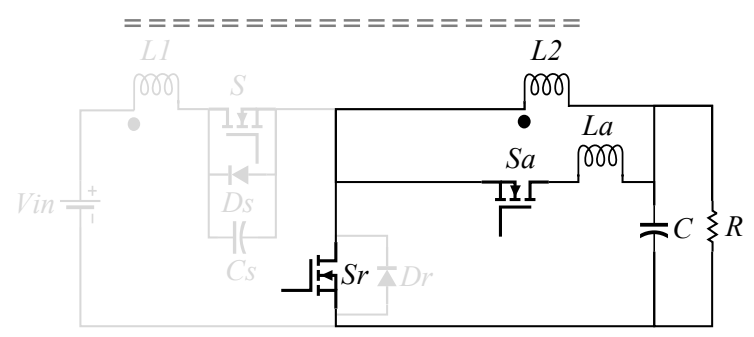

(b)

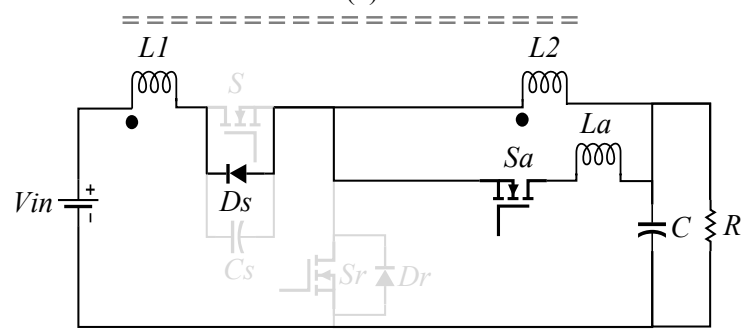

(d)

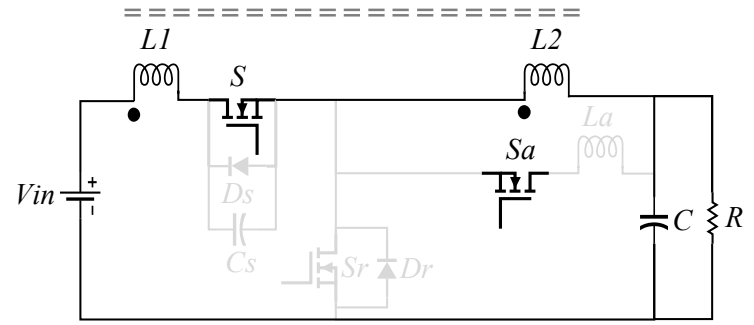

(f)

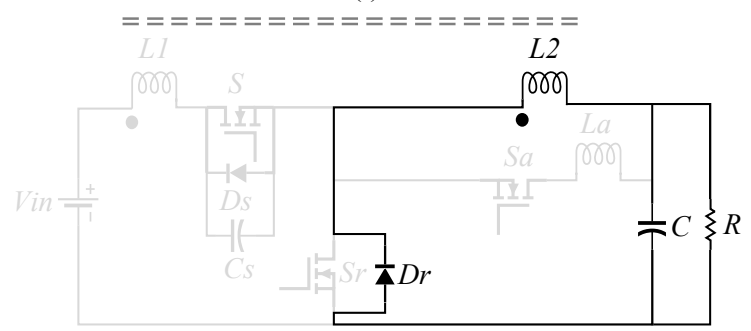

(h)

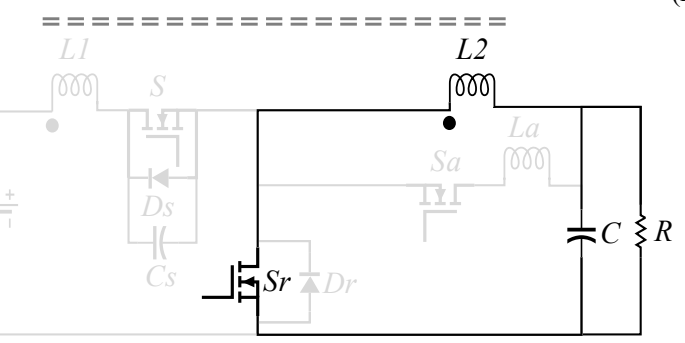

(i)

Figure 3. Equivalent operating modes [12]

(a) Mode $1\left[\mathrm{t}_{0}-\mathrm{t}_{1}\right]$ (b) Mode $2\left[\mathrm{t}_{1}-\mathrm{t}_{2}\right]$ (c) Mode $3\left[\mathrm{t}_{2}-\mathrm{t}_{3}\right]$ (d) Mode $4\left[\mathrm{t}_{3}-\mathrm{t}_{4}\right]$ (e) Mode $5\left[\mathrm{t}_{4}-\mathrm{t}_{5}\right]$ (f) Mode $6\left[\mathrm{t}_{5}-\mathrm{t}_{6}\right]$ (g) Mode $7\left[\mathrm{t}_{6}-\mathrm{t}_{7}\right]$ (h) Mode $8\left[\mathrm{t}_{7}-\right.$ $\left.t_{8}\right]$ (i) Mode $9\left[t_{8}-t_{9}\right]$

\section{PASSIVE COMPENSATION FOR CONDUCTED EMI REDUCTION}

In this section, the prediction of conducted electromagnetic emissions of the converter is presented. The parasitic $\mathrm{CM}$ capacitors in the converter are illustrated in Fig. 4. Other parasitics are ignored to avoid the complexity. A passive method is considered in this paper to reduce the common-mode EMI generated by the parasitic capacitor of the main switch. This parasitic capacitor exists between the drain node and earth including heat-sink capacitance.
The EMI reduction method considered in this paper is based on the generating negative capacitance to cancel the drain-earth parasitic capacitance. Passive techniques for generation of the negative capacitor are investigated in [14]. One technique is shown in Fig. 5 using a capacitor connected to earth and a coupled inductor with turn-ratio, $n_{c}$ [14]. According to this figure, using the circuit decoupling and Y- $\Delta$ conversion, a negative capacitor can cancel the parasitic capacitor at node 2 to reduce the commonmode noise current. The coupling coefficient, $k$ in Fig. 5 is considered 1 to extract the decoupling circuit. 


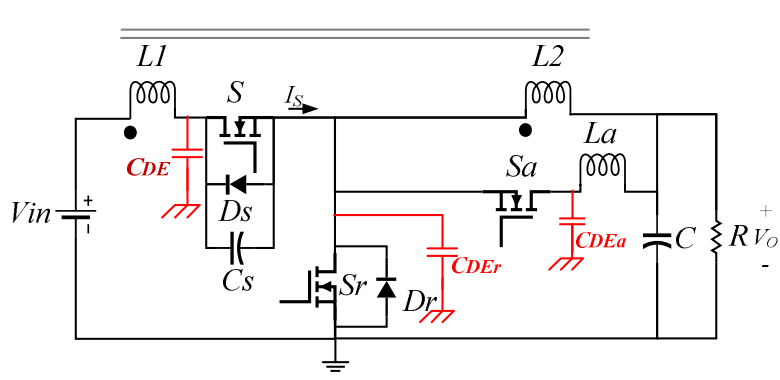

Figure 4. The converter model with heat-sink parasitic capacitors

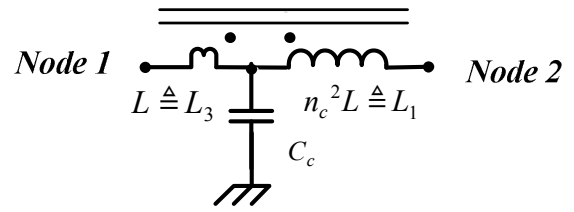

Decoupling

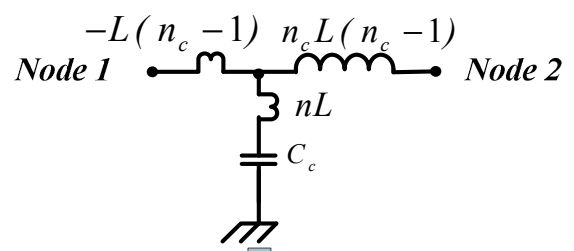

Y-4 Conversion

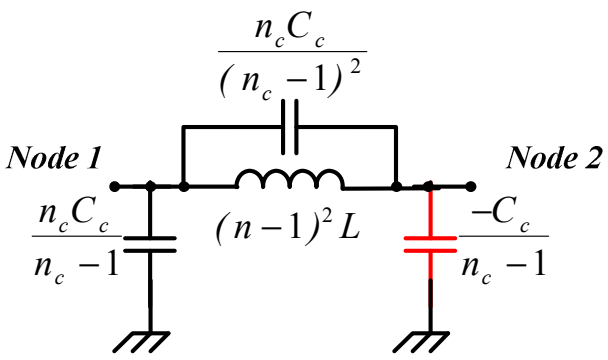

Figure 5. Passive compensation method to generate the negative capacitance.

The EMI reduction method shown in Fig. 5 is applied to the high step-down converter (Fig. 4) for EMI reduction. Fig. 6 shows the proposed converter considering the heat-sink parasitic capacitors. The focus of this paper is to cancel the CM noise current caused by the capacitor of the main switch including its heat-sink capacitor. This capacitor has more effect on CM-EMI in comparison to synchronous and auxiliary switch capacitors due to high $\mathrm{dv} / \mathrm{dt}$ and voltage spike of the main switch caused by the leakage inductance.

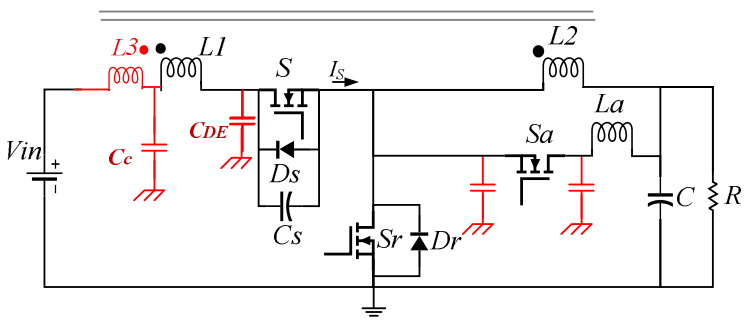

(a)

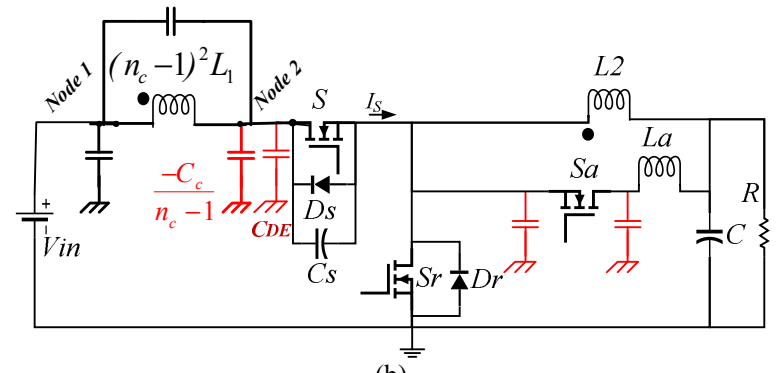

(b)

Figure 6. a) the proposed converter by applying the negative capacitance generation $b$ ) equivalent circuit of the proposed converter

\section{DESIGN PROCEDURE AND SIMULATION RESULTS}

The $100 \mathrm{~W}$ soft-switching high step down converter is designed and simulated for $150 \mathrm{~V}$ input voltage and $24 \mathrm{~V}$ output voltage and the operating frequency of the converter is $100 \mathrm{kHz}$. The relation between $L_{2}$ and $L_{1}$ is determined by the turn-ratio, $n$ using:

$$
\frac{L_{2}}{L_{1}}=\left(\frac{n_{2}}{n_{1}}\right)^{2}=n^{2}
$$

According to the basic design equations of the tappedinductor buck converter, the value of $L_{1}$ and $L_{2}$ are defined as $300 \mu \mathrm{H}$ for $n=1$. The $L_{1} / L_{3}$ in the proposed converter (Fig.6(a)) is also obtained by the turn-ratio, $n_{c}$ and $L_{3}$ is calculated equal to $3 \mu \mathrm{H}$ for $n=10$ :

$$
\frac{L_{3}}{L_{1}}=\left(\frac{n_{3}}{n_{1}}\right)^{2}=\frac{1}{n_{c}{ }^{2}} .
$$

The conversion gain of the converter is obtained using a volt-second balance by the following:

$$
\frac{V_{o}}{V_{i n}}=\frac{D}{1+\frac{1}{n}(1-D)} .
$$

For $150 \mathrm{~V}$ input voltage and $24 \mathrm{~V}$ output voltage, the duty cycle of the converter is calculated around 0.27 using (8). The value of $C_{S}$ is obtained like other turn-off snubber capacitor $[12,13]$ as below:

$$
C_{S_{\min }}=\frac{I_{S W} \cdot t_{f}}{2 \cdot V_{S W}} .
$$

where $I_{S W}$ is the switch current before turn-off, $V_{S W}$ is the voltage after turn-off and $t_{f}$ is the switch current fall time. To ensure soft switching situation, $C_{s}$ is selected higher than $C_{S \min }$ and is chosen $2.2 \mathrm{nF}$. The value of $L_{a}$ is determined like regular turn-on snubber inductor $[12,13]$ as $3 \mu \mathrm{H}$.

$$
\frac{-C_{c}}{n_{c}-1}+C_{D E} \simeq 0
$$

The drain-earth synchronous rectifier and auxiliary switch capacitor are estimated 50 and $30 \mathrm{pF}$ and drainearth capacitor of the main switch, $C_{D E}$ is considered $100 \mathrm{pF}$ due to larger heat-sink. To cancel $C_{D E}$, the compensation capacitor, $C_{c}$ is $900 \mathrm{pF}$ by (10). 
For the simulation, IRF740 is chosen for $\mathrm{S}$ and IRF640 is used for Sr. IRF640 with a series diode is used in the simulation model for Sa. The coupling coefficient is assumed around 0.99. the higher coupling coefficient results in a better EMI reduction. The simulation of voltage and current waveforms of the switches are shown in Fig. 7.

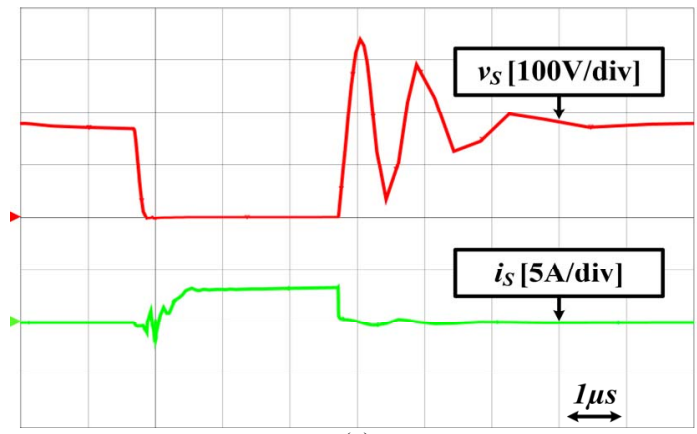

(a)

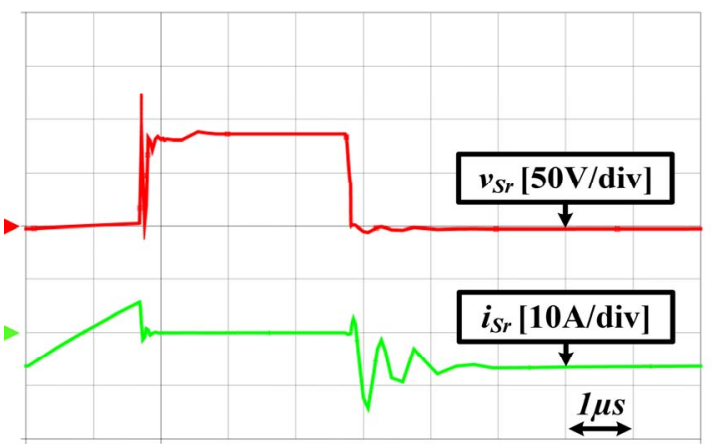

(b)

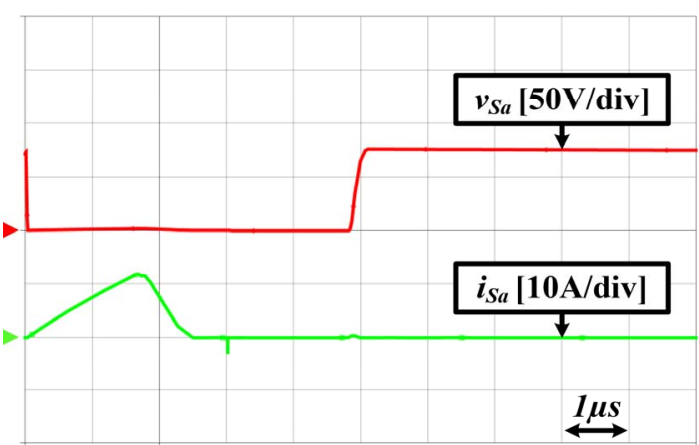

(c)

Figure 7. Simulated voltage and current waveforms of the proposed converter

(a) main switch (b) synchronous switch (c) auxiliary switch

Fig.7(a) shows the ZV operation of the main switch. The auxiliary circuit at turn-on instant provides the condition for soft switching and the body diode of the switch conducts before switch turn-on instant so the main switch turns on under ZV. In addition, the snubber capacitor provides the ZVS condition for turning off. However, the leakage inductance of the tapped inductor causes voltage spikes at turn-off instant. The waveforms of the synchronous rectifier are shown in Fig.7(b). It is turned on under ZVS because of its body diode and an auxiliary circuit. Snubber capacitor of the main switch provides ZVS condition at turn-off instant. The leakage inductance causes some differences between theoretical analyses and the simulation result of synchronous rectifier voltage. Fig.7(c) shows ZCS operation of the auxiliary switch. It turns on and off under ZCS because of the inductor that is placed in series with the auxiliary switch.

To predict the conducted EMI of converters in Fig. 4 and Fig.6(a), line impedance stabilization networks (LISNs) model according to CISPR22 are used in OrCAD software where are connected between the input line and the input of the converters. The simulation results of the conducted emissions (positive input line) of the soft switching high step converter (Fig.4) and the proposed converter with passive compensation (Fig.6(a)) are illustrated in Fig.8(a) and Fig.8(b), respectively. According to this figure, the EMI main peak is significantly reduced from $1.05 \mathrm{~V}$ to around $400 \mathrm{mV}$ by applying the passive compensation method.

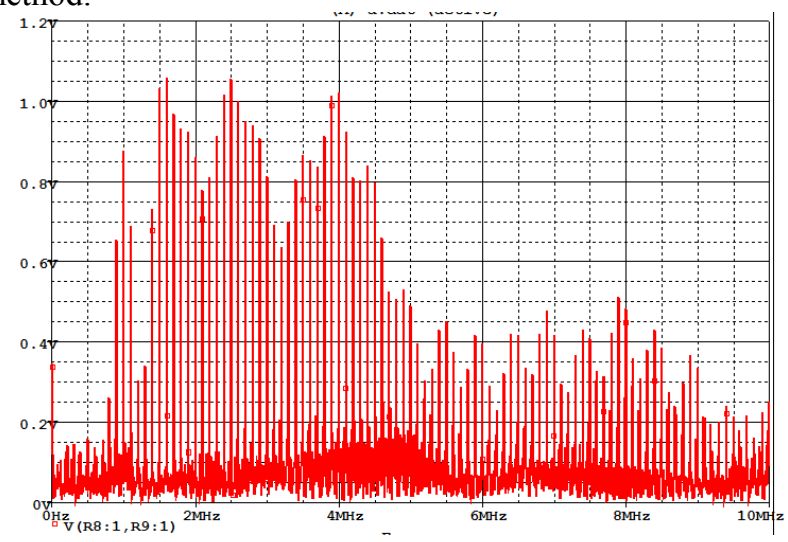

(a)

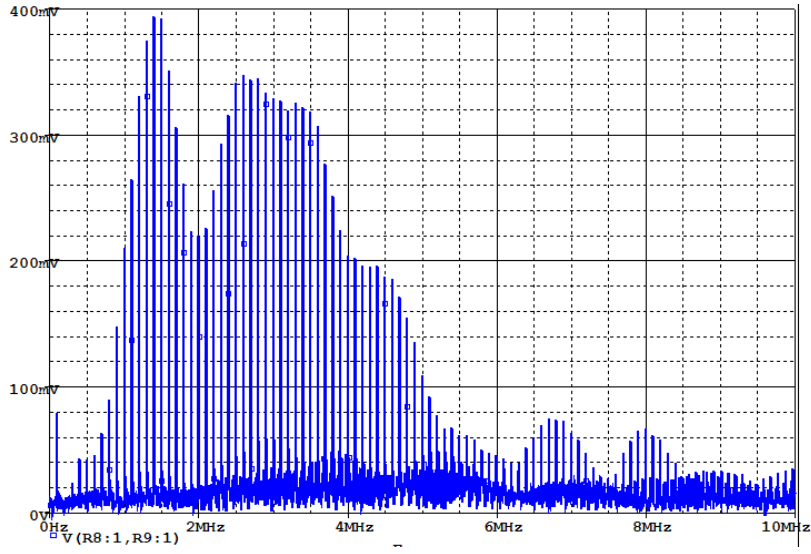

(b)

Figure 8. Predicted conducted EMI of a) high step converter (Fig.4) vertical scale:0-1.2v

b) proposed converter with passive compensation (Fig.6(a)) vertical scale:0-400mv, horizontal scale: $0-10 \mathrm{MHz}$

\section{CONCLUSION}

In this paper, a high step down converter with an auxiliary circuit is studied. Duty cycle is extended by using a coupled inductor. Turning on the main switch and the synchronous rectifier is done under ZVS because the auxiliary circuit provides a condition to achieve soft switching. Due to the existence of the snubber capacitor, their turning off is done under ZVS. Furthermore, the turn-on and turn-off of the auxiliary switch are under ZCS. The conducted EMI discussion by considering drain-earth switch capacitance between is presented and a passive compensation method for conducted EMI reduction is applied to reduce the 
conducted electromagnetic emissions. The simulation results of a $100 \mathrm{~W}-100 \mathrm{kHz}$ confirmed the theoretical analysis. The conducted EMI prediction verified the proper reduction of the electromagnetic emissions in the proposed converter.

\section{REFERENCES}

[1] J. Viinamäki, J. Jokipii, T. Messo, T. Suntio, M. Sitbon, and A. Kuperman, "Comprehensive dynamic analysis of photovoltaic generator interfacing DC-DC boost power stage," IET Renewable Power Generation, vol. 9, pp. 306314, April 2015.

[2] H. Wu, P. Xu, H. Hu, Z. Zhou and Y. Xing, "Multiport converters based on integration of full-bridge, and bidirectional DC-DC topologies for renewable generation systems," IEEE Trans. Ind. Electron., vol. 61, pp. 856-869, Feb. 2014.

[3] H. Sira-Ramirez, and M. A. Oliver-Salazar, "On the robust control of buck-converter DC-motor combinations," IEEE Trans. Power Electron., vol. 28, pp. 3912-3922, Aug. 2013.

[4] M. G. Kim, "Error amplifier design of peak current controlled (PCC) buck LED driver," IEEE Trans. Power Electron., vol. 29, pp. 6789-6795, Dec. 2014.

[5] L. Chen, H. Wu, Y. Xing, and X. Xiao, "Performance evaluation of a $1 \mathrm{~kW}$ non-isolated high step-up/step-down bidirectional converter for distributed battery storage system," IEEE 2nd International Future Energy Electronics Conf. (IFEEC), Taipei, pp. 1-5, 2015.

[6] E. Adib and H. Farzanehfard, "Zero-Voltage-Transition PWM Converters With Synchronous Rectifier," IEEE Trans. Power Electron., vol. 25, no. 1, pp. 105-110, Jan. 2010.

[7] D. Maksimovic, and S. Cuk, "Switching converters with wide DC conversion range," IEEE Trans. Power Electron., Vol. 6, pp.151-157, Jan. 1991.

[8] K. Yao, M. Ye, M. Xu, and F. C. Lee, "Tapped-inductor buck converter for high step down DC-DC conversion," IEEE Trans. Power Electron., vol. 20, pp. 775-780, July 2005.

[9] X. Wei, C. Luo, H. Nan, and Y. Wang, "A simple structure of Zero-Voltage-Switching (ZVS) and Zero-Current Switching (ZCS) buck converter with coupled inductor," Journal of Power Electronics, vol. 15, pp. 1480-1488, Nov. 2015.

[10] L. Jiang, C. C. Mi, S. Li, C. Yin, and J. Li, "An improved soft-switching buck converter with coupled inductor," IEEE Trans. Power Electron., vol. 28, pp. 4885-4891, Nov. 2013.

[11] S. S. Lee, "Step-down converter with efficient ZVS operation with load variation," IEEE Trans. Ind. Electron., vol. 61, pp. 591-597, Jan. 2014.

[12] A. Ariyan, MR. Yazdani, "Zero-Voltage-Transition Buck Converter for High Step-Down DC-DC Conversion with Low EMI," Journal of Power Electronics, vol 17, no. 6, pp. 14451453, Nov. 2017

[13] A. I. Pressman, Switching Power Supply Design, 2nd ed. New York: McGraw-Hill, 1998.

[14] S. Wang, FC. Lee, "Analysis and applications of parasitic capacitance cancellation techniques for EMI suppression," IEEE Trans. Ind. Electron., vol. 57, no. 9, pp. 3109-3117, Sep. 2010. 